\title{
Transformações no mundo do trabalho e a emergência de um novo trabalhador: a experiência do Consórcio de alumínio do Maranhão
}

Antonio Marcos Gomes-Mestre em Ciências Sociais pela Universidade Federal do Maranhão/ UFMA. E-mail: amg_cs@yahoo.com.br

Marcelo Sampaio Carneiro - Doutor em Sociologia pelo Programa de PG em Sociologia da Universidade Federal do Rio de Janeiro/UFRJ e professor do Programa de Pós Graduação em Ciências Sociais da Universidade Federal do Maranhão/UFMA. E-mail: mdscarneiro@uol.com.br

\section{Resumo}

Este estudo analisa o processo de transformação na gestão da força de trabalho realizada pelo Consórcio Alumar, indústria de produção de alumínio primário localizada em São Luis/MA, após o processo de reestruturação produtiva vivenciada por essa empresa no decorrer da década de 1990. A análise das mudanças observadas teve como foco a tentativa de compreender os impactos dessas transformações sobre o perfil da mão-de-obra contratada por essa indústria, bem como perceber que tipos de impactos essas novas exigências promoveram nas atividades de trabalho de um grupo específico de operários da empresa, os chamados operadores.

\section{Palavras chave}

Sociologia do trabalho; processo de trabalho; reestruturação produtiva; qualificação profissional, indústria do alumínio.

\begin{abstract}
This survey deals with the manpower management change that occurred at the Consórcio de Alumínio do Maranhão Alumar, primary aluminum and alumina plant, located in Sao Luis, Maranhão, after production reorganization conducted by this industry during the 90's decade. The change management analysis was focused to understand the impacts on Alumar's contracted manpower profile as well as to identify how the new requirements changed the work activities of a specific company group: the plant operators.
\end{abstract}

\section{Key words}

Sociology of labor; Labor process; Production reorganization; Aluminum Industry 


\section{INTRODUÇÃO}

Este artigo analisa o processo de reestruturação produtiva ocorrido na empresa Consórcio de Alumínio do Maranhão (Alumar), na década de 1990, discutindo o impacto dessa reestruturação sobre a qualificação e o engajamento dos trabalhadores.

A Alumar se instalou em São Luís no início da década de 1980 e desde esse período é a principal unidade industrial localizada no Maranhão, além de ser um dos maiores complexos mundiais produtores de alumínio primário e alumina. Compõem o consórcio, as duas maiores produtoras mundiais de alumínio, a norteamericana Alcoa, que é a acionista majoritária e responsável pelo gerenciamento do consórcio e a canadense Alcan. Além destas, temos a mineradora anglo-australiana BHP Billiton e Abalco, empresa subsidiária da Alcoa.

Para garantir a melhor rentabilidade e se manter competitiva no mercado a Alumar tem investido continuamente no alcance de novos patamares de produtividade e de melhoria na qualidade de seus produtos, adotando tecnologias ${ }^{1}$ que geram modificações tanto na chamada base técnica (máquinas, energia, informatização produtiva) quanto nos modelos de organização e gestão do trabalho (toyotismo).

O presente artigo analisa os efeitos dessas inovações técnico-organizacionais sobre os trabalhadores, tendo em vista as adequações que são exigidas destes para se adaptarem às constantes transformações no processo produtivo da empresa. O trabalho de pesquisa foi realizado mediante observações no ambiente fabril da Alumar, acesso aos materiais produzidos pela empresa relacionados à temática em discussão, conversas informais e entrevistas semi-estruturada com trabalhadores da empresa.

\section{O TRABALHADOR DA ALUMAR}

O Consórcio Alumar possuía em 31 de julho de 2006, 1.904 funcionários distribuídos em três grandes áreas: Redução, onde estavam lotados 65\% dos funcionários, Refinaria com $27 \%$ e $8 \%$ na área administrativa. Essa divisão é realizada pela empresa levando em consideração o tipo de atividade realizada em cada uma dessas áreas, sendo assim, na Refinaria, os funcionários estão envolvidos com o refino da bauxita para obtenção de óxido de alumínio (alumina); na

1 Utilizamos a definição de tecnologia proposta por Afonso Fleury que, fundamentado em Sabato e Mckenzie (1981), a define como: "um pacote de informações organizadas, de diferentes tipos (científicas, empíricas ...), provenientes de várias fontes (descobertas cientificas, patentes, livros, manuais, desenhos ...), obtidas através de diferentes métodos (pesquisa, desenvolvimento, cópia, espionagem ...) utilizada na produção de bens e serviços" (1993, p. 34). 
Redução, trabalha-se com a produção de alumínio primário; e os funcionários da área administrativa ou PAE, buscam oferecer suporte às atividades realizadas na Refinaria e Redução.

No que tange ao pagamento de salários e ao horário de trabalho, a empresa adota dois sistemas, um deles é o chamado horário administrativo, que funciona de segunda a sexta-feira, com folga aos sábados, domingos e feriados, com o expediente iniciando às $7 \mathrm{~h} 30$ e encerrando às $16 \mathrm{~h} 30$, nesse sistema o funcionário tem o mês como referência para o cálculo do seu salário, sendo chamado de mensalista.

O outro sistema, denominado horário fixo pela empresa, destina-se basicamente aos operadores, eletricistas mecânicos e instrumentistas, e serve para atender as demandas do processo produtivo, que funciona de forma ininterrupta. Nesse sistema, os empregados trabalham oito horas por dia, durante seis dias de forma ininterrupta, folgando dois dias e são pagos por hora trabalhada, sendo chamados de horistas.

O trabalho do operador de uma indústria de processo contínuo, como é o caso da Alumar, se caracteriza pela ausência de controle efetivo sobre o processo produtivo, embora, segundo Agier e Guimarães (1995, p. 42), um operador não perca completamente o controle sobre o seu processo de trabalho, pois ele continua sabendo "quando, como e onde intervir, e a natureza dos riscos envolvidos, tanto para a vida dos equipamentos quanto para as vidas humanas".

Segundo dados fornecidos pela empresa, os operadores constituem a maioria dos funcionários da Alumar, representando, em julho de 2006, 51\% do total de funcionários, ou seja, 972 operadores de um total de 1904 empregados.

O nível de escolaridade dos operadores naquele período, estava concentrado no ensino médio, com 94\%, enquanto a média geral dos funcionários era de $82 \%$, sendo que cinco operadores tinham o ensino superior completo, quinze com curso superior em andamento e 12 deles possuíam o nível fundamental. $\mathrm{Na}$ média geral, o percentual de funcionários com ensino superior perfazia 16\% e nível fundamental $1 \%$.

A média de idade dos operadores acompanhava a média geral dos funcionários da empresa, com percentuais bem próximos: $56 \% / 54 \%$ na faixa etária entre 36 a 50 anos, 3\%/4\% acima de 51 anos, para operadores e média geral, respectivamente, destacando-se que essas duas faixas etárias juntas, agregavam percentualmente mais pessoas do que a outras faixas etárias, que eram de $37 \% / 35 \%$ para aqueles que tinham entre 26 a 35 anos e $4 \% / 7 \%$ para os que tinham entre 18 e 25 anos. 
A maioria dos operadores estava há mais de dez anos na empresa (57\%), enquanto a média geral era de 49\%. Com até cinco anos de trabalho, havia 23\% de operadores, percentual que chega a 33\% se for observada a média geral. Entre 6 e 10 anos de serviço, havia $23 \%$ de operadores e 19\% na média geral.

\section{O PROCESSO DE REESTRUTURAÇÃO PRODUTIVA REALIZADO PELA EMPRESA}

O complexo industrial da Alumar começou a ser implantado em 1979, e sua produção foi iniciada em agosto de 1984, com capacidade para produzir 500 mil toneladas de alumina e 110 mil toneladas de alumínio por ano, passando até o ano de 1990, por mais três ampliações, quando foi possível aumentar a produção de alumínio para 345 mil toneladas/ano.

Nesse intervalo de tempo entre o inicio das operações e a conclusão das expansões os dirigentes norte-americanos, que haviam sido responsáveis pela parte de construção, gradativamente, foram substituídos por executivos brasileiros no comando da empresa. Além dos estrangeiros, no período de construção, a mão de obra qualificada era proveniente principalmente dos estados de São Paulo e Minas Gerais, onde havia unidades da Alcoa, encarregados em repassar os conhecimentos sobre organização industrial para funcionários recém admitidos (DURANS, 2000).

Estando numa fase de consolidação, a empresa tem como meta primeira captar pessoas pré-dispostas ao trabalho na indústria, tendo como critério básico de seleção a avaliação da capacidade física dessas pessoas, para num segundo momento trabalhar na formação/capacitação de seus operários.

No início da década de 1990, o consórcio Alumar completa seu processo de implantação com a conclusão da fase III, tornando-se o maior produtor brasileiro de alumínio e um dos maiores do mundo. Até o ano de 2004, nenhum outro investimento de grande porte foi efetuado pelo consórcio para ampliar suas instalações e desse modo aumentar sua capacidade produtiva.

A empresa passa a ter como foco a modernização do seu processo produtivo, se inserindo em definitivo no processo de reestruturação produtiva em curso no mundo desde 1973, com a emergência daquilo que Harvey (1993) denomina acumulação flexivel. A empresa para se adequar ao cenário de intensa concorrência existente no mundo capitalista, passa a adotar diferentes estratégias para se tornar competitiva, como: racionalizações de custos e ajustes administrativos (redução de salários e de quadro de pessoal), a adoção de novos padrões organizacionais e de gestão da mão-de-obra. 
Após ter recrutado e formado seus primeiros operários, tendo como critério básico de seleção o nível de força física e exigindo o mínimo de qualificação possível, a Alumar, na medida em que se propõe a alavancar seus padrões de qualidade e competividade, se depara com a necessidade de modificar o perfil da sua mão de obra, tendo em vista:

um novo tipo de padrão de gestão da força de trabalho, que implicaria a mudança de um modelo baseado no uso extensivo da mão-de-obra semiqualificada, para outro baseado no uso intensivo de mão-de-obra qualificada, polivalente e cooperativa (GITAHY; RABELO, 1993, p. 10).

Buscando ajustar sua mão-de-obra às exigências que eram postas pelos novos parâmetros de produtividade e qualidade, a empresa desenvolve um programa de complementação educacional em parceria com o SENAI, criando turmas especiais para aqueles operários que não haviam concluído o ensino fundamental e o ensino médio, sendo que a partir de 1992, o ensino médio torna-se a exigência mínima para quem deseja ingressar na empresa.

Tal ênfase na elevação do nível de escolaridade de seus operários é condizente com exigência do paradigma produtivo ora em curso, conforme nos assegura Ribeiro (ano?, p. 673-674):

Com as inovações organizacionais e tecnológicas dos anos 80, alteram-se as exigências quanto ao perfil da mão-de-obra. Os trabalhadores devem apresentar novas qualidades como conhecimentos práticos e teóricos, decisão, comunicação e capacidade de abstração. A reestruturação produtiva exige não mais especialista mas sim um generalista, capaz de realizar várias atividades. O perfil da mão-de-obra no novo paradigma altera-se radicalmente. Assim, o nível de escolaridade da força de trabalho passa a ser considerado um fator chave.

No decorrer da década de 1990, a empresa, baseando-se nas chamadas melhores práticas empresariais (benchmarking), sobretudo de origem japonesa, implementa algumas inovações organizacionais visando melhorar seu processo produtivo (atividades produtivas, serviços, atividades administrativas), adotando, por exemplo, os princípios do Controle Estatístico do Processo (CEP), concebidos por Joseph M. Juran e Deming relacionados ao uso de dados estatísticos (gráfico de Pareto) como ferramenta para tomada de decisões e gestão da qualidade.

Outra inovação organizacional, a reengenharia (reengineering), concebida por James Champy e Michel Hammer, causou um grande impacto na empresa. Segundo Albuquerque (2002, p. 263), ela teria um princípio racionalizador, no sentido de intervir no processo produtivo e nas decisões gerenciais a partir de critérios econômicos (maximização e otimização dos recursos) e uma perspectiva democrática no sentido de permitir o compartilhamento, com toda a empresa, das 
metas que devem ser operacionalizadas por coletividades diferenciadas, segundo suas atribuições e funções na estrutura organizacional.

Com a aplicação dos princípios da reengenharia e do downsiz̨ing (redução hierárquica), departamentos e/ou áreas inteiras da empresa foram extintos ou terceirizados, como restaurante, serviços gerais, segurança patrimonial, dentre outras, além disso, foi feita uma revisão do processo, do conjunto de tarefas e atividades realizadas na empresa, acabando por extirpar funções consideradas a partir de então como desnecessárias e que estariam dificultando uma maior agilidade aos negócios da companhia, conforme menciona o então gerente de Recursos Humanos da empresa, em entrevista a Durans (2000, p. 70-71):

Então quando cheguei, tive que estancar uma série de coisas. O cabide de empregos era enorme, a quantidade de pessoas sem qualificação era muito grande, por que trabalhavam aqui com volume, então o cara não era muito bom, contrata outro e outro, bota cinco para fazer a função de um. Quando nós terminamos a construção, que foi em 1989, aí começou o processo de aculturar para a produtividade.

O Gráfico 1 com o demonstrativo dos funcionários da Alumar de 1984 a 2005 nos oferece um importante indicativo do processo de reestruturação verificado na empresa, que tem o ano de 1990, como divisor desse processo, ali conclui-se a fase três de construção da Alumar, e inicia-se a redução de pessoal mencionado acima pelo então gerente de Recursos Humanos.

Redução que só vai se atenuar a partir de 1997, quando a empresa passa a adotar, de forma sistêmica, a filosofia do toyotismo, implantando o chamado Alcoa Business System (ABS), a partir dessa data haverá certo equilíbrio no número de funcionários efetivos da empresa.

Há de se ressaltar que o Gráfico 1 exemplifica três momentos da empresa, o primeiro (1984-1986) referente ao período de consolidação e estruturação da empresa, quando se fez necessário recrutar maciçamente mão-de-obra, o segundo (1990-1996) marca o processo de reestruturação, mencionado agora há pouco e um terceiro momento, que tem seu marco inicial em 1997, quando a empresa passa a investir em produtividade sem aumentar significantemente seu número de pessoal, conforme orienta o toyotismo - que se estrutura a partir de um número mínimo de trabalhadores - passando a trabalhar os chamados aspectos subjetivos do trabalhador. 


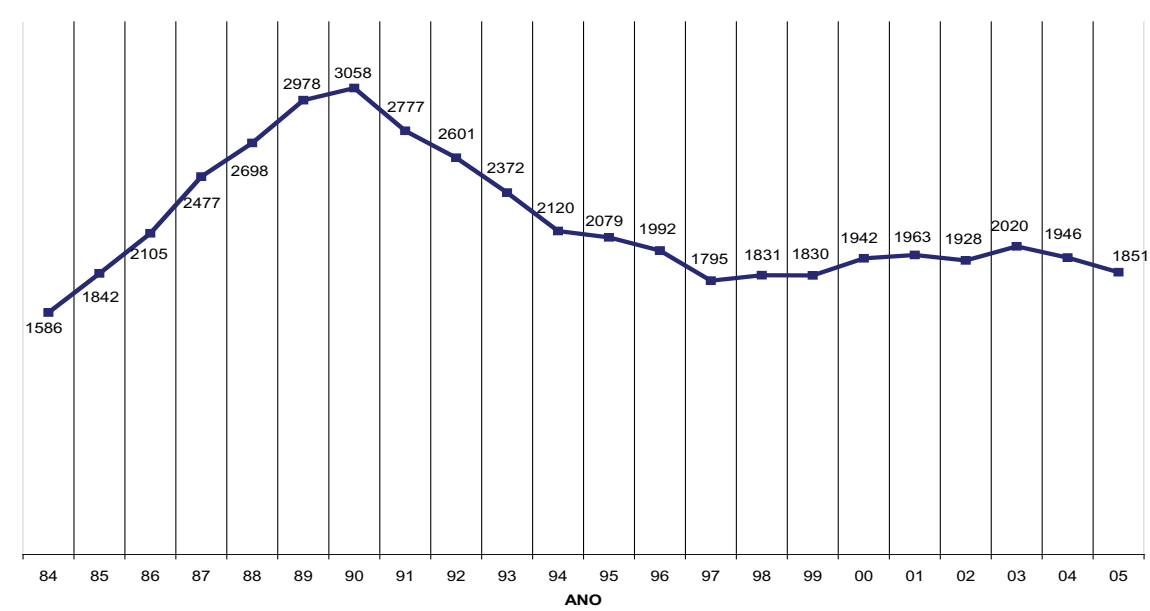

Gráfico 1 Quadro com o efetivo de funcionários da Alumar de 1984 a 2006 Fonte: Arquivos Alumar (ano?)

Além dos princípios da reengenharia, a empresa adotou de 1990 a 1996, o Total Quality Management (TQM), baseado nos Programas de Qualidade Total japoneses, visando a melhoria do processo produtivo, a qualidade dos produtos, a redução de custos através da eliminação de defeitos/desperdícios e do não-trabalho e uma maior participação dos empregados nos processos de tomada de decisão (LARANGEIRA, 2002, p. 250).

Entretanto, segundo depoimentos colhidos, embora o TQM tenha contribuído para a melhoria do processo produtivo realizado na empresa, seus efeitos não teriam sido homogêneos em toda a companhia, obtendo resultados significativos em determinados setores, mas sendo ineficiente em outros, no entanto, preparou o terreno para a implantação do sistema Toyota de Produção a partir de 1997.

O TPM (Total Productive Maintenance) ou Manutenção Produtiva Total começa a ser implantado em 1993. Por meio desse programa, os operadores, além de realizarem as suas atividades de operação, são capacitados para realizar tarefas de limpeza, lubrificação, inspeção, reaperto, reparos eletromecânicos e realização de melhorias nas máquinas e equipamentos que utilizam, na tentativa de gerar o chamado senso de propriedade dos operadores em relação a esses equipamentos.

Embora não tenha aumentado no decorrer da década de 1990 sua capacidade produtiva por meio da ampliação das suas instalações físicas ao mesmo tempo em que reduziu seu número de funcionários, a Alumar obteve melhorias 
significativas na sua capacidade produtiva conforme a Tabela 1 , indicando que as inovações técnico-organizacionais implementadas na empresa contribuíram significativamente para o alcance desses índices.

Tabela 1 - Evolução da capacidade de produção da Alumar (fase inicial e em 2005)

\begin{tabular}{|l|c|c|c|c|}
\hline & Início & $\begin{array}{c}\text { Capacidade Inicial } \\
\text { (t/ano) }\end{array}$ & $\begin{array}{c}\text { Capacidade em } \\
2005(\mathrm{t} / \mathrm{ano})\end{array}$ & $\begin{array}{c}\text { Custos Construção } \\
\text { (US\$) }\end{array}$ \\
\hline Porto & Set. 1983 & 1.800 .000 & 4.200 .000 & $274 \mathrm{M}$ \\
\hline Refinaria & Mai. 1984 & 500.000 & 1.500 .000 & $560 \mathrm{M}$ \\
\hline Redução - LI & Jul. 1984 & 110.000 & 127.082 & $372 \mathrm{M}$ \\
\hline Redução - LII & Fev. 1986 & 135.000 & 155.738 & $213 \mathrm{M}$ \\
\hline Redução - LIII & Set. 1990 & 83.000 & 97.180 & $308 \mathrm{M}$ \\
\hline Total Redução & - & 328.000 & 380.000 & $893 \mathrm{M}$ \\
\hline Total Planta & - & - & - & $1.727 \mathrm{M}$ \\
\hline
\end{tabular}

Fonte: ALUMAR, 2005

As mudanças realizadas pela empresa não foram aceitas passivamente pelos funcionários, conforme ressalta Durans (2000), afirmando que no período compreendido entre 1990 e 1994, houve uma acirrada disputa ideológica entre capital e trabalho no chão de fábrica: "De um lado a direção da empresa tentando mudar o perfil técnico e ideológico da força de trabalho para implementar seus novos métodos de gerenciamento, e de outro os trabalhadores tentando organizarse como categoria e reivindicar seus direitos" (DURANS, 2000, p. 91).

Além das inovações organizacionais, a empresa adere à chamada Terceira Revolução Industrial, que se baseia no uso intensivo da microeletrônica e das tecnologias de informação, acarretando na automatização do processo produtivo:

A automatização do processo produtivo eleva a preocupação das empresas com a qualificação e as habilidades profissionais, que emergem como importantes capacidades produtivas a serem utilizadas. Os sistemas automatizados são sistemas abertos, permanentemente em evolução, e esta se vale muito do feedback que vem do chão da fábrica. A automação flexível exige, então, um novo tipo de tarefa ligada ao conhecimento do sistema produtivo e à necessidade de prever e corrigir disfunções do sistema. A nova qualificação exigida nas tarefas industriais compreende os seguintes elementos: novos conhecimentos práticos e teóricos, capacidade de abstração, decisão e comunicação, e qualidades relacionadas à atenção e interesse pelo trabalho (RIBEIRO (ano?), p. 675).

Apesar da avaliação das condições físicas ser um critério básico para a contratação de um operador, já que a realização de exames e aprovação por uma equipe médica é condição sine qua non para o candidato participar do processo 
seletivo propriamente dito, a ênfase no vigor físico, feita em outros momentos pela empresa, perde um pouco sua importância para dar lugar a outros critérios de seleção.

Com o ABS, a Alumar desenvolve aquilo que Alves (2005) denomina toyotismo sistêmico, cujo objetivo seria a captura da subjetividade operária pelo capital, integrando de forma sistêmica ferramentas organizacionais baseadas no toyotismo, sendo que algumas destas haviam sido adotadas anteriormente pela empresa principalmente como estratégias de racionalização de custos, causando reações entre os trabalhadores, daí seu caráter restrito, segundo Alves.

Desde sua implantação, o ABS veio obtendo avanços consideráveis na mobilização da subjetividade operária em prol dos negócios da empresa, aumentando os índices de produtividade e qualidade.

Em paralelo a esse sistema de negócios, nos últimos dez anos (1996-2006), um outro fenômeno vem causando impactos sobre o operariado da Alumar, cuja influência não se restringe ao ambiente fabril, manifestando-se em outras esferas da vida social, criando a demanda por um perfil de trabalhador atento às chamadas questões da agenda sócio política e exigindo deste uma nova postura/atitude frente a essas questões e consequentemente, formatando um novo saber-ser operário.

Trata-se daquilo que a antropóloga Lívia Barbosa (2002) denomina novas tecnologias gerenciais, construídas sob o bojo da chamada cultura de negócios ${ }^{2}$. As tecnologias gerenciais se pautam na adoção por parte das empresas de algumas questões da agenda sócio-política das sociedades contemporâneas, especialmente aquelas trazidas pelos chamados novos movimentos sociais e sua transformação em algo do tipo empreendedorismo social, learning organization, cultura organizacional, diversidade, empresa ecologicamente responsável, capital intelectual e qualidade, dentre outras.

Há de se ressaltar, como nos alerta Lívia Barbosa, que a implementação dessas tecnologias gerenciais não indica um abandono da lógica econômica por outra de cunho mais social por parte das empresas transnacionais, a aferição de lucro continua a ser a mola propulsora dessas empresas, o interessante é compreender por que elas têm hoje, "que obter lucro de uma determinada maneira e, em particular, por meio da transformação da agenda social e política em tecnologias gerenciais" (BARBOSA, 2002, p. 212).

2 Definida como uma série de fluxos culturais (repertórios de imagens, valores, símbolos e significados) que permeiam o discurso e a atividade empresarial e gerencial das empresas transnacionais, multinacionais e/ou globalizadas, a cultura de negócios funcionaria como um arcabouço ideológico do mundo empresarial, explicando e justificando o que mudou, por que mudou e o que deve ser feito para a organização continuar sobrevivendo com sucesso (BARBOSA, 2002, p. 213). 
Portanto, a partir do processo de reestruturação produtiva implantado na empresa, consoante com a implementação de novas tecnologias gerenciais, percebe-se ações desencadeadas pela Alumar, no sentido de promover e requerer mudanças nos aspectos atitudinais e comportamentais dos funcionários, conforme destacado no tópico seguinte.

\section{REESTRUTURAÇÃO PRODUTIVA E SEUS IMPACTOS SOBRE O TRABALHADOR DA ALUMAR}

Neste trabalho, busca-se deteremos nos chamados aspectos subjetivos do trabalhador, tentando compreender a questão da fabricação, produção, moldamento da subjetividade operária (PELBART, 2000), a partir das vivências e experiências adquiridas no ambiente fabril da Alumar, concebendo o trabalhador enquanto sujeito afetado pelas normas sociais e imbricado nas tramas que definem essas normas, e não utilizando as concepções de sujeito autônomo e livre, associadas à ideia de indivíduo (NARDI; TITONI; BERNARDES, 2000).

No cenário atual em que "o capitalismo tardio, multinacional, global, globaritário, mundial integrado tomou de sobressalto a subjetividade para investila numa escala nunca vista" (JAMESON apud PELBART, 2000), e onde as "máquinas tecnológicas de informação e de comunicação operam no coração da subjetividade humana, não só na sua memória, na sua inteligência, mas também na sua sensibilidade, nos seus afetos, nos seus fantasmas conscientes" (GATTARI, apud PELBART, 2000, p. ...) tem-se a produção daquilo que Michel Hardt denomina trabalho imaterial, no sentido de em vez de se fabricar apenas carros ou sapatos, passa-se a produzir imagens, informação, conhecimentos, serviços e num segundo sentido produz-se a subjetividade humana, que ao lado das relações intelectuais e valores afetivos, "passam a ocupar um lugar cada vez mais central do processo produtivo" (PERBALT, 2000, p. 36).

É este movimento que é percebido no Consórcio de Alumínio do Maranhão, a construção, captura e mobilização da subjetividade operária, que não se restringe ao atendimento dos ditames do processo produtivo realizado dentro da fábrica, mas a ultrapassa, inserindo-se em outras esferas e espaços da vida cotidiana, numa simbiose entre a esfera produtiva e a reprodutiva.

Ao longo da história da Alumar, a implementação de inovações tecnológicas e organizacionais gradativamente vai substituindo um tipo de operação baseada no esforço físico e no trabalho manual, por um processo automatizado e repleto de procedimentos, normas e prescrições, exigindo uma ampliação do conhecimento operário sobre a produção, produzindo uma tendência de maior intelectualização 
Transformações no mundo do trabalho e a emergência de um novo trabalhador: a experiência do consórcio de alumínio do Maranhão

do trabalho de produção, que se torna mais cognitivo e abstrato, conforme percebemos em relato ${ }^{3}$ a seguir:

Pergunta: Comparando as atividades que um operador faz hoje, com as que ele fazia antes, que diferenças você percebe?

Resposta: Houve de mudança é a exigência maior do cargo em termos teóricos, a responsabilidade aumentou, porque você termina um curso tem que preencher relatórios, e fazer de forma correta, não tentar de forma nenhuma fazer erradamente porque você estará sendo desonesto, ainda mais que tem o princípio da empresa, honestidade faz parte, nós temos que ser honestos, não deu pra resolver pede ajuda pra alguém, porque é o correto (Magno Cubas, entrevista realizada em 21.06.2006).

R: O segundo grau. Hoje, eles pedem segundo grau, noções de informática, você faz prova de português, matemática. Na verdade a empresa hoje tenta pegar aqueles que já chegue aqui pronto, tem esses computadores aí, então, você vai aprender? Não, você já vem com a noção daquilo, é isso, se não sabe é mais lento, não mais difícil, mais lento (Mário Cubas, entrevista realizada em 26.06.2006).

P: Tu falaste que as exigências são maiores, o que é exigido de vocês agora? R: Maior no sentido de conhecimento teórico e ações imediatas, porque a um tempo atrás não! Se tinha um problema, passava para um outro turno, entende-se que pelo menos isso era atraso, perda, hoje não, você toma ação imediata, é feed back direto, se tem um problema eu chego posso conversar com o gerente e ele conversa comigo numa boa, agora existe todo um sistema de respeito, todo um sistema de política, mais exigente e cada vez melhor, se eu não desenvolvo um produto que tenha condições de competir, eu vou fechar, por isso o cara tem que entrar aqui com esse pensamento, enfrentar isto como se fosse um vestibular, encaro isto aqui hoje dessa forma, algum tempo atrás tu era promovido pela idade e trabalho bruto, direto na máquina, hoje não, além da teoria tu tens que ter a teoria e a prática, antes era só a prática, pra você ser promovido passa mais tempo, tem gente que tem quatro, cinco anos e ainda não foi promovido, até mesmo pelo grau de instrução que não era exigido antes o segundo grau, entrava qualquer pessoa, hoje não, exige-se o segundo grau ou nível técnico, preferencialmente (Magno Cubas, entrevista realizada em 21.06.2006).

Pelos depoimentos, se percebe que a exigência por uma maior capacidade cognitiva não se restringe ao processo produtivo, que demanda por noções mais acuradas de informática e dos conhecimentos adquiridos no ensino médio, mas está relacionada a uma maior capacidade de compreensão e absorção de forma correta dos chamados princípios, políticas, valores e normas mandatórias difundidas pela empresa, na habilidade em saber resolver os problemas da área sob sua responsabilidade, e, por conseguinte na capacidade em saber relacionar-se/

3 Os nomes adotados aqui são fictícios, fazendo-se menção no "sobrenome" do entrevistado à área em que este trabalha na Alumar. 
comunicar-se com quem preciso for para a resolução desses problemas.

Aqui você tem que ser você, se você tiver que esperar por alguém praticamente você não trabalha aqui, porque como eu te falei a máquina tá muito enxuta, hoje não tem encarregado, hoje só tem o back up, depende muito de você, da sua vontade de ir lá, e resolver as pendências, querer, por isso estou falando que querer pra mim hoje é primordial, por que se diz iniciativa, iniciativa está muito relacionada ao querer, se não quiser, não se ajeita (Mario Cubas, entrevista realizada em 26.06.2006).

A necessidade de se obter um trabalhador com maior nível de conhecimento, responsabilidade, poder de decisão, onde as hierarquias gerenciais se afrouxam para dar espaço a formas mais participativas e descentralizadas leva necessariamente à constituição do chamado trabalhador autônomo e com iniciativa ${ }^{4}$.

De trabalhador ou empregado, o operador adquire o estatuto de colaborador, internalizando as responsabilidades pela produção, tais como: "preparar a máquina, zelar pela qualidade do produto, pela produtividade e pela manutenção da máquina, podendo ser deslocado para outro posto de trabalho ou fabricar outro tipo de produto, caso a produção necessite".

A mobilização da subjetividade do trabalhador e a consequente ampliação de suas responsabilidades são efeitos diretos das inovações tecnológicas e organizacionais implementadas pela empresa, conforme percebido por Pereira (1997) em trabalho de meados da década de 1990, sobre as novas formas de organização do trabalho e seus impactos sobre a saúde do trabalhador, e que ainda são percebidos pelos trabalhadores da Alumar:

ABS, TPM, DMS, tudo isso aumenta a responsabilidade do operador, que ele é quem faz acontecer, nós estamos aqui para manter o sistema de forma responsável, então traz benefícios em termos de resolução de problemas de forma mais rápida, mas aumenta a responsabilidade de quem executa, quando você aumenta algo pra você seja prático ou teórico, seu corpo trabalha menos, sua mente trabalha mais, isto é a realidade, alguém pode pensar diferente também, o nível de responsabilidade aumenta e você tem que estar preparado (Magno Cubas, entrevista realizada em 21.06.2006).

4 Para Zarifian (2003, p. 87): “O conceito de autonomia traz, na empresa, uma nova definição das relações de poder, dos campos legítimos de ação e na maneira de definir as regras de trabalho. Ele autoriza a definição das áreas de autonomia e traz também uma certa forma de engajamento do sujeito em relação a si mesmo. Condiciona e solicita a mobilização da competência. Ser autônomo não e apenas definir suas próprias regras de ação; é agir por si mesmo, resolver por si mesmo. É, aliás, o significado comum da palavra autonomia (a autonomia de uma criança, por exemplo, quando consegue andar por si mesma). O conceito de iniciativa, no entanto, significa a competência em si mesma, em ação, o engajamento do sujeito não em relação a regras (sejam elas determinadas ou autônomas), mas em relação a um horizonte de efeitos, aqueles que sua iniciativa singular provoca. Eu estaria propenso a dizer, de forma concisa: a competência é a iniciativa sob a condição de autonomia; é determinar um começo em uma área de indeterminação". 
De forma semelhante, Pereira (1997), ao comentar sobre a adesão dos trabalhadores ao TPM, afirma que assim como este, "[...] todas as estratégias de controle da força de trabalho para o aumento da produtividade criam uma carga de responsabilidade e tensão, principalmente em função da pressão feita pelos líderes para o cumprimento das metas produtivas da fábrica”, gerando o que ela denomina desgaste mental.

Tendência que é verificada nas falas dos trabalhadores, onde se percebe que a implementação de novas tecnologias, com destaque para aquelas oriundas do chamado plano de sugestões (onde se tem a massiva participação dos operadores) vêm promovendo a diminuição do esforço físico nas atividades operacionais, enquanto o chamado esforço mental aumenta:

Pergunta: Com relação a esforço físico e stress como tu avalias?

O esforço físico ele diminuiu, como eu te falei o próprio processo mudou, o stress na verdade depende muito do fator psicológico, de cada pessoa, depende muito de cabeça, mas eu acho que antes existia menos, acho que apesar daquele serviço bem braçal antigamente, acho que tinha bem menos pessoas stressadas, bem menos chefes stressados, bem menos operadores stressados, hoje nós somos mais, talvez seja pela pressão, isso talvez tenha aumentado isso aí, antigamente as pessoas eram bem menos (Mario Cubas, entrevista realizada em 26.06.2006).

Não deixa de ter, acho que aumentou, com a mudança tecnológica a responsabilidade aumenta, você tem que estar preparado para isso, e isto está diretamente ligado a mente do cara, quando você tem que trabalhar muito a mente o stress aumenta, você tem que ter a responsabilidade do tempo, você tem que controlar isso aí, e fazer algo para que diminua, porque hoje é difícil uma pessoa não ter stress, é um problema mundial de saúde, e que eu passo no dia a dia (Magno Cubas, entrevista realizada em 21.06.2006).

Embora os trabalhadores citem algumas ações desenvolvidas pela empresa no intuito de dirimir as condições e fatores de risco existente nos locais de trabalho, as falas dos operadores nos indicam que seus ritmos de trabalho ainda estão presos aos imperativos da producão, seja no cumprimento das chamadas metas de produtividade, seja pela ocorrência daquilo que Zarifian (2001, p. 40) denomina evento, entendido "como o que ocorre de maneira parcialmente imprevista, inesperada, vindo perturbar o desenrolar normal do sistema de produção, superando a capacidade da máquina de assegurar sua auto-regulagem".

Entretanto, o controle sobre o processo de trabalho não se dá nos mesmos moldes do paradigma taylorista-fordista, onde se tinha a figura do inspetor monitorando o tempo e movimento realizado pelos trabalhadores e o cumprimento de suas metas de produção, e principalmente prescrevendo o que o trabalhador deveria fazer. 
Muito embora as chefias vistoriem o cumprimento das metas de trabalho de seus subordinados, esse monitoramento se orienta no sentido de auferir se os resultados estão sendo alcançados. Para o alcance de tais resultados, de acordo com Zarifian (2003), a hierarquia não faz determinações sobre a forma de como alcançá-los e nem estabelece objetivos claramente definidos para as equipes e indivíduos, e sim espera a tomada de iniciativa destes diante de situações marcadas pelo imprevisível, nesse sentido: "podemos dizer que o resultado é aquilo a que a iniciativa deve levar (alcançar), mas não aquilo pelo qual é dirigida" (ZARIFIAN, 2003, p. 90). Sobre essa questão um dos operadores comenta:

Ai de quem não tiver (iniciativa, autonomia) na hora certa, e ai de quem tiver na hora errada, mas nós temos hoje uma cadeia de ajuda, você tem um tempo determinado pra resolver um problema, se não, usa a cadeia de ajuda, até chegar, por exemplo, no gerente da refinaria (Renato do COR, entrevista realizada em 28.07.2006).

Situações como a cadeia de ajuda, citada acima levam para aquilo que Zarifian, apoiado em Hannah Arendt, denomina comunidade de ação, formada para lidar com situações que requerem, cada vez mais, uma pluralidade de profissões (funcionamento em redes, em projetos, etc), com entrecruzamento de setores especializados e se definindo pelo engajamento temporal e pelos efeitos procurados em conjunto, e não mais, segundo Zarifian (2003, p. 114), em referência a um mesmo "círculo profissional" e relativamente a um mesmo "produto".

Com relação às hierarquias, as mudanças de seus papéis se expressam lexicalmente na denominação gestor (em lugar de chefe) e colaborador (em vez de empregado). Tais mudanças tiveram seu início ainda no começo da década de 1990, com a reengenharia e especialmente o downsizing (redução hierárquica), e continua com a extinção gradativa dos níveis hierárquicos intermediários, sobretudo encarregados que, diminuídos em número, passam cada vez mais a exercer funções burocráticas e de gestão de pessoal, enquanto a coordenação da execução de tarefas operacionais passam cada vez mais a serem realizadas pelos team liders ou backup de área em conjunto com os operadores da sala de controle.

De lá pra cá praticamente tirou muito encarregado, a chefia do alto escalão, de certa forma encolheu, quem é chefe aqui, é chefe ali, a empresa hoje não consegue ter chefes aqui nessa sala, tem que ser daqui, tem que ser dali, e esse quadro ele tá diminuindo, e acredito que ele vai ser único, um só vai fazer isso, eu acho que essa aí é a grande mudança desse quadro todo aí, a chefia está sendo enxugada, a operação também, na verdade (Mario Cubas, entrevista realizada em 26.06.2006).

Segundo Coriat (1994. p. 77-78), a estrutura hierárquica piramidal pensada pelo taylorismo-fordismo é abalada e repensada para dar lugar a uma estrutura mais "horizontalizada", já que "a rigidificação da separação funcional não pode 
ser mantida. Ela nada mais é que um obstáculo à competividade e valorização do capital" surgindo a chamada fábrica transfuncional, onde a regra é pensar pelo avesso: partindo do mercado para garantir permanentemente a adaptabilidade da empresa à mudança, tornando-se imperiosa uma mudança em relação a estrutura hierárquica anterior.

Além das mudanças na estrutura e reconfiguração dos papéis designados à hierarquia da Alumar, os operadores sentem os impactos dessas inovações tecnológicas e organizacionais na redução do número de funcionários necessários para realizar determinada atividade e o conseqüente aumento da sobrecarga de trabalho:

Acho que é positivo (as inovações) porque de certa forma ficou mais fácil a comunicação diretamente, há algum tempo atrás, tinha aquelas restrições todas, não podia falar com certas pessoas, sempre falar com o chefe imediato, hoje não existe isso, mas a não ser, a exigência continua maior, porque ao mesmo tempo em que a tecnologia entrou, as pessoas saíram, eram cinco pessoas em cada equipe, hoje são três, continua trabalhando bastante ( Mario Cubas, entrevista realizada em 26.06.2006).

O grande problema é que com essa organização houve uma enxuga no número de funcionários, por conta dessa organização, se tirou uma pessoa de cada grupo, se tirou uma quantidade de pessoas, isso não é bom para o trabalhador, já para a indústria, que busca a redução de custos e ela investe em tecnologia, então ela tem que ter o ganho, tem que ter o retorno desse investimento, então ela demitiu algumas pessoas e pra ela a redução de custos é bom, lógico, pra todo negócio a redução de custos é bom, o aumento da produção é bom, a capacitação do funcionário é bom, hoje ela tem um funcionário multifuncional, então é ótimo (Renato do COR, entrevista realizada em 28.07.2006).

A lógica da redução de pessoal está assentada na ideia de fábrica minima defendida por Ohno, segundo o qual: “atrás do estoque há um 'excesso de pessoas' empregadas em relação ao nível da demanda solúvel e efetivamente escoada” (apud CORIAT, 1994, p. 33). Para ele, há duas maneiras de se aumentar a produtividade, uma delas se assenta no modelo norte americano de aumentar as quantidades produzidas e a outra se baseia na redução do pessoal de produção, o que implica em repensar, em todos os seus detalhes, a organização do trabalho (OHNO, apud CORIAT, 1994, p. 33).

No caso da Alumar, esse pensamento tem como conseqüência a pressão feita sobre a empresa para que ela possa atingir índices satisfatórios de produtividade com o mínimo de pessoal efetivo possível, conforme observado em algumas ocasiões, quando o Consórcio era comparado com outras unidades da Alcoa espalhadas pelo mundo e o critério de avaliação era a capacidade produtiva da 
empresa versus quantidade de mão de obra empregada, ou então quando alguns afirmavam: "nossos visitantes dizem que nosso processo é fabuloso, temos bons resultados, mas afirmam que temos gente demais trabalhando aqui".

A redução do número de funcionários se deve à aplicação dos princípios toyotista da fábrica minima e do método Kanban, e tem como efeito a desespecializaçãa e intensificação do trabalho, conforme previsto pelo próprio Ohno (CORIAT, 1994, p. 54). Sobre essa questão da desespecialização e intensificação do trabalho, veja o relato do operador abaixo:

A empresa por ser um capital estrangeiro, ela tem também uma política estrangeira, uma política de primeiro mundo aonde venha a reduzir o custo, aonde venha aumentar a produção, né? Aumentar a capacidade de produtividade do funcionário, aumentar o conhecimento do funcionário, pra que um funcionário possa exercer mais de uma função, ou possa ser multifuncional, para que ele não seja um funcionário voltado só para uma tarefa específica, então o perfil de um trabalhador da Alumar e da Alcoa hoje, eu comparo ao perfil de um astronauta, eu identifico muito o perfil do astronauta com o perfil do trabalhador da Alcoa, parece brincadeira mais é verdade, onde a pessoa tem que ter a capacidade de aprendizado, tem de ter a capacidade de ser submisso, tem de ter a capacidade de tomar decisões, tem de ter capacidade de fazer acontecer, tem de ter a capacidade de não se zangar com colega, de não tá com problemas pessoais aonde o coletivo tem que tá atuando, enfim, é um perfil mutante, não é um perfil padrão, aliás, o perfil padrão todos tem que ter, que é o perfil mutante, eu tenho que tá mudando, até porque a empresa também é uma empresa que tá em mutação, a empresa muda 24 horas por dia, né, hoje se pode isso, amanhã não pode mais, hoje se faz isso amanhã não se faz mais aquilo, se vive em experimentos, se vive em estratégias, se vive em condições de está sobrecarregado de tarefas pra ver qual a capacidade, qual o estado ideal que a gente pode tá trabalhando (Renato do COR, entrevista realizada em 28.07.2006).

Dentre as modalidades ou métodos de treinamento destaca-se a formação no local de trabalho (on the job training), prática que consiste no revezamento dos operários nos postos de trabalho, adquirindo o saber fazer e habilidades diversificadas.

A Alumar em si não exige grandes conhecimentos, ele tem que aprender a trabalhar no equipamento, certo? Se ele se dispor a ter uma pessoa que ensine pra ele, e ele também saiba procurar aí com os eletricistas, com mecânicos, saber aquele básico, ele mesmo tem que procurar buscar, porque a Alumar ela não exige assim, Olha! Você pra subir naquela máquina ali, você tem que ter curso superior, não, vai depender de cada pessoa, se você quer subir de grau, quer aprender, então, você tem que buscar, você tem que ir atrás (Ribamar Porto, entrevista concedida em 14.06.2006)).

A outra modalidade de treinamento é a formação "fora da oficina" (offthe-job-training), levada a efeito pela própria empresa, que podem ser longas ou de 
Transformações no mundo do trabalho e a emergência de um novo trabalhador: a experiência do consórcio de alumínio do Maranhão

curta duração, sendo que a ascensão profissional do operador, conforme prevê a carreira por habilidades, vai se dando de acordo com aquisição desse saber fazer legitimado pela empresa através dos seus instrutores e oferecida conforme as necessidades de formação dos operadores.

Se for preciso, nós temos treinamento de mecânica, nós temos treinamento de elétrica, nós temos treinamento de primeiros socorros, nós temos treinamentos operacionais diretamente relacionados aquela tarefa que a pessoa vem trabalhando, forno, sistemas, caldeiras, ninguém vai pra área á toa, todo mundo é treinado. (João do Eletrodo, entrevista realizada em 26.06.2006).

Eu sempre digo que uma coisa que eu acho boa na Alumar, é que na Alumar você não faz nada sem saber, se não souber, ela vai mandar te treinar, tu tem que ser treinado praquilo, então pra você resolver os problemas que tem lá na área, eu como operador de cubas fui treinado praquilo, pra cada problema daquele que tiver lá (Mario Cubas, entrevista realizada em 26.06.2006).

Assim como na execução de suas tarefas de trabalho, exige-se que os trabalhadores sejam autônomos e tenham iniciativa também pelo seu processo de formação e aquisição do saber fazer, sendo responsabilizados individualmente em atualizar e validar regularmente seus treinamentos para evitar a obsolescência e o desemprego.

P: Com relação ao tipo de habilidades, que tipos de habilidades, características o senhor precisa para ter êxito na função de operador?

R: Em primeiro lugar vontade de aprender, se você não tiver vontade de aprender não adianta, acho que o principal é isso aí, porque se não tiver vontade de aprender não aprende, por melhor que você venha preparado, como já teve pessoas formadas, chegaram aqui e não conseguiram segurar, eu acho que a vontade que faz a diferença, independente se ser ou não ser, a vontade ela é um diferencial (Mario Cubas, entrevista realizada em 26.06.2006).

P: Quais são as características que uma pessoa precisa ter para atuar na Alumar? R: A característica não precisa ter nenhuma, basta ele querer saber aprender, ele se dispor a aprender e a chefia também dar oportunidade pra ele, porque não adiante você vir pra cá ser um operador um e você ficar de braço cruzado que você não aprende nada, se você não sair pro campo, não se dispor, se você não sair aprendendo, sair perguntando, então a pessoa não está querendo saber nada, a pessoa tem que saber de disputa, tem que saber aprender, se desenvolver, pra poder chegar ao ideal da Alumar (Mario Cubas, entrevista realizada em 26.06.2006).

Os conhecimentos adquiridos na empresa pelos trabalhadores não se referem apenas ao saber fazer operacional, mas também ao saber ser, que está relacionada não somente ao ato de assumir responsabilidades frente às situações de trabalho complexas, mas também está atrelada à dimensão ética, de tomar uma posição 
diante dos problemas do mundo e da capacidade em cuidar do outro, como prevê as chamadas tecnologias gerenciais (BARBOSA, 2002), cujo campo de ação extrapola os limites da fábrica e se insere na vida cotidiana dos seus funcionários.

Nessa relação, a subjetividade operária passa a ser formatada não apenas para atuar no ambiente fabril, mas também em outras esferas e espaços da vida desses trabalhadores, acompanhando um movimento mais geral em que o capitalismo se estende a todos os campos sociais, "não só extensivamente, num novo colonialismo, mas intensivamente, numa espécie de endocolonialismo" (PELBART, 2000, p. 33).

Dessa forma, os trabalhadores que têm sua subjetividade e o seu saber ser mobilizados no decorrer do processo de trabalho, também são convocados a pôlos em prática (e nesse sentido são avaliados), em outros espaços da vida cotidiana, seja na realização de atividades ligadas às chamadas tecnologias gerenciais da empresa, seja na propagação do conhecimento adquirido na empresa para outros segmentos sociais ou mesmo no processo de mudança comportamental que lhes são exigidos dentro da fábrica.

Segundo Pelbart (2000, p. ...), a interpenetração entre vida e trabalho tem como uma de suas conseqüências a transformação da subjetividade "não só num capital insubstituível, mas também o epicentro de toda poiesis [...] Pois se é claro que o capital se apropria da subjetividade em escala nunca vista, a subjetividade é ela mesma um capital de que cada um dispõe, virtualmente, com conseqüências políticas a determinar."

É essa subjetividade enquanto capital, que é avaliada pelas empresas quando saem em busca daquilo que Haefliger (2005) denomina "assalariado ideal segundo o gerenciamento pós-moderno".

Segundo Haefliger, as empresas, tenderiam a realizar o chamado "gerenciamento anti-teflon", cuja função seria verificar se o candidato "cola" ao perfil do posto, comunga com os valores da empresa, ou seja, "exige in fine que o colaborador funda-se com a empresa em uma díade ingênua".

$\mathrm{Na}$ Alumar, com relação aos operadores, observa-se os intuitos do "gerenciamento anti-teflon" na realização do Programa de Formação de Operadores (PFO), onde após a realização de um processo seletivo os participantes passam por um treinamento de capacitação dentro da fábrica durante três meses, após o qual, os participantes passam a fazer parte do banco de dados da empresa e são admitidos à medida que surgem vagas.

Alguns autores apontam que a tendência às mudanças nas práticas de gestão de pessoas tem sido verificada não só em empresas americanas e européias, mas em empresas brasileiras. Ressaltam que: 
Transformações no mundo do trabalho e a emergência de um novo trabalhador: a experiência do consórcio de alumínio do Maranhão

nos tradicionais processos de recrutamento e seleção, novos instrumentos, novas técnicas vêm sendo empregados, visando identificar pessoas com potencial de crescimento, flexibilidade para enfrentar incidentes críticos e as novas demandas da empresa, pensamento estratégico. Os processos de treinamento e desenvolvimento assumem novos contornos, criando-se, inclusive em algumas empresas o conceito de universidade corporativa; o ponto chave desse conceito é que todo o processo de desenvolvimento das pessoas deve estar alinhado à definição das estratégias de negócio e competências essenciais da organização. E, por fim, em termos do sistema de remuneração, algumas empresas começam a desenvolver modelos próprios, estabelecendo os níveis de competência e a compensação condizente com cada nível (FLEURY; FLEURY, 2001, p. 65).

Dentre as características ou perfil do que deveria ser um operador da Alumar, o sr. Mario Cubas emite a seguinte opinião: O que queira aprender e tiver boa vontade, manso, nada de arrogância, a Alumar não quer ninguém arrogante. Já o Sr Mário Cubas afirma: Pra ser operador, em primeiro lugar ele tem que ter responsabilidade, diálogo, e eu diria também, condições físicas, né? Boa saúde. Enquanto Carlos da CVI define da seguinte forma: Pessoas com visão holística, que seja perceptivo, que tenha ideias novas, com visão ampla do futuro e que traga beneficios para a empresa.

\section{CONSIDERAÇÕES FINAIS}

Conforme visto no decorrer deste artigo, a Alumar tem procurado constantemente implementar inovações técnico-organizacionais a fim de melhorar seu processo produtivo e a gestão de sua mão-de-obra, se constituindo num dos principais complexos industriais produtores de alumínio primário e alumina do mundo.

Sua instalação em São Luís, a partir de 1980, causou grande impacto na economia e na sociedade local. No entanto, seu legado mais importante para este estudo, refere-se a constituição do principal grupo de trabalhadores industriais maranhenses.

A implementação de inovações tecnológicas e organizacionais ao longo da história da Alumar vem exigindo uma ampliação do conhecimento operário sobre a produção, o que aliado às especificidades do trabalho desenvolvido numa indústria de processo contínuo como a Alumar, produz a tendência de maior intelectualização do trabalho, que se torna mais cognitivo e abstrato

Essa intelectualização do operariado não se restringe ao processo produtivo, tornado mais automatizado e repleto de procedimentos, normas e prescrições, e que demanda por noções mais acuradas de informática e dos conhecimentos adquiridos no Ensino Médio, ou seja, do saber fazer, mas também à questão do saber ser, que está relacionada não somente às situações de trabalho, mas também 
à dimensão ética, do tomar uma posição diante das problemáticas do mundo e da capacidade em cuidar do outro, como requerem as chamadas tecnologias gerenciais (BARBOSA, 2002).

Essa dimensão do saber ser é requerida constantemente na execução das tarefas de trabalho desses operadores, exigindo-se que sejam autônomos e tenham iniciativa, internalizando as responsabilidades pela produção, após adquirir o estatuto de colaborador, com habilidade em saber resolver os problemas da área e, por conseguinte na capacidade em saber relacionar-se/comunicar-se com quem preciso for para a resolução desses problemas.

Nessa nova estrutura organizacional, as hierarquias gerenciais se afrouxam para dar espaço a formas mais participativas e descentralizadas. No entanto essa estrutura é acompanhada pela redução do efetivo de pessoal, acarretando a ampliação do nível de responsabilidades dos operadores, e consequentemente acelerando seu ritmo e intensidade de trabalho, ocasionando por vezes o chamado desgaste mental ou stress.

No entanto, para os operadores da ALUMAR, que vivem no contexto de um mercado de trabalho bastante limitado - o trabalho industrial representa apenas $6 \%$ do conjunto a oferta de empregos no Maranhão (PNAD, 2005) - manter o posto de trabalho na empresa representa um imperativo, com poucas alternativas de escape.

\section{REFERÊNCIAS}

AGIER, Michel; GUIMARÃES, Antonio Sérgio; CASTRO, Nadya Araújo. Imagens e identidades do trabalho. São Paulo: Orston/Hucitec, 1995.

ALBUQUERQUE, Paulo P de. Reengenharia In: CATTTANI, Antonio David (org). Dicionário crítico sobre trabalho e tecnologia. 4. ed. ver. ampl. Petrópolis: Vozes; Porto Alegre: Ed. da UFRGS, 2002.

ALVES, Giovanni. O novo (e precário) mundo do trabalho: reestruturação produtiva e crise do capitalismo. São Paulo: Boitempo, 2005.

BARBOSA, Lívia. Globalização e cultura de negócios. In: KIRSCHENER, Ana Maria; GOMES, Eduardo R; CAPPELLIN, Paola (Orgs.). Empresa, empresários e globalização. Rio de Janeiro: Relume/Dumará, 2002.

CORIAT, Benjamin. Pensar pelo avesso: o modelo japonês de trabalho e organização. Rio de Janeiro: Revan; UFRJ, 1994. 
Transformações no mundo do trabalho e a emergência de um novo trabalhador: a experiência do consórcio de alumínio do Maranhão

DURANS, Cláudia Alves. A reestruturação produtiva e os impactos sobre os trabalhadores: o caso da Alumar em São Luis-MA. Dissertação (Mestrado em Serviço Social) - Programa de Pós-Graduação em Serviço Social, UFPB, João Pessoa, 2000.

FLEURY, Antonio; FLEURY, Maria Teresa. Estratégias empresariais e formação de competências. Rio de Janeiro: Atlas, 2001. p. 64.

FLEURY, Afonso Carlos C. Novas tecnologias, capacitação tecnológica e processo de trabalho: comparações entre o modelo japonês e o brasileiro. In: HIRATA, Helena. Sobre o modelo japonês: automatização, novas formas de organização e de relações de trabalho - São Paulo: Editora da Universidade de São Paulo, 1993. p. 33-47.

GITAHY, Leda; RABELO, Flávio. Educação e desenvolvimento tecnológico: o caso da indústria de autopeças, Educação e Sociedade, n. 45, 1991

HAEFLIGER, Stéphane. $\mathbf{O}$ assalariado ideal segundo o gerenciamento pósmoderno, In: le mond diplomatique Brasil, 1/05/2004. disponível em: http:/ / diplo.uol.com.br/2004-05,a909, Acesso em: 07 ago. 2006.

HARVEY, David. Condição Pós Moderna: uma pesquisa sobre as origens da mudança Cultural. São Paulo: Loyola, 1993.

LARANJEIRA,. Sonia M. G. Fordismo e pós-fordismo. In: CATTANI, Antonio David (org). Dicionário crítico sobre trabalho e tecnologia. 4. ed. rev. ampl. Petrópolis: Vozes; Porto Alegre: UFRGS, 2002. p. ...-...

NARDI, Henrique Caetano; TITTONI, Jaqueline; BERNARDES, Jefferson Souza. Subjetividade e Trabalho. In: CATTANI, Antonio David (org). Dicionário crítico sobre trabalho e tecnologia. 4. ed. ver. ampl. Petrópolis: Vozes; Porto Alegre: UFRGS, 2002. p. ...-...

PELBART, Peter Pál. A vertigem por um fio: Políticas da subjetividade contemporânea. São Paulo: Iluminuras, 2000.

PEREIRA, Carla Regina Assunção. As novas formas de organização do processo de trabalho e o desgaste mental: "hoje, a gente trabalha o esforço físico e o esforço psicológico”. 1999. Monografia (Graduação em Ciências Sociais) Universidade ...., São Luis, 1999. 
Antonio Marcos Gomes • Marcelo Sampaio Carneiro

RIBEIRO, Rosana A. Educação básica e perfil da mão-de-obra: o caso da indústria de calçados. In: Associação Brasileira de Estudos do Trabalho, V Encontro Nacional.

ZARIFIAN, Philippe. O modelo da competência: trajetória histórica, desafios atuais e propostas. São Paulo: Editora Senac, 2003.

Objetivo competência: por uma nova lógica. São Paulo: Atlas, 2001. 